\section{El embarazo en la adolescente precoz}

La población mundial de adolescentes ha ascendido a más de 1000 millones y en los países en desarrollo una de cada cuatro personas está en la adolescencia, a diferencia de una de cada siete en los países desarrollados. El embarazo a edades cada vez más tempranas se está convirtiendo en un problema social y de salud pública de alcance mundial. Afecta a todos los estratos sociales, pero predomina en las clases de bajo nivel socioeconómico, en parte debido a la falta de educación sexual y al desconocimiento de los métodos de control de la natalidad. En un estudio reciente en Venezuela se compararon la morbilidad y la mortalidad materna y perinatal de 284 adolescentes de 10 a 14 años de edad con las de un número igual de controles de 20 a 24 años. Se analizaron el estado civil, control prenatal, número de gestaciones, terminación del embarazo, tipo de parto, duración del trabajo de parto, complicaciones durante el embarazo, parto y puerperio, y permanencia en el hospital de las madres, así como el peso, talla, sexo, Apgar y morbilidad y mortalidad de los recién nacidos.

En relación con la edad se encontró que 229 de las adolescentes tenían 14 años, 41 tenían 13, nueve tenían 12 , dos tenían 11 y tres de ellas, 10 años. Como era de esperar, la gran mayoría de ellas (94\%) eran solteras. Entre los controles, la edad se distribuyó más uniformemente, con 77 de 24 años, 56 de 20 y el resto entre esos dos extremos. Eran solteras $70,4 \%$. Hubo una diferencia significativa en el número de gestaciones, ya que $97,2 \%$ de las adolescentes eran primigestas (en ocho pacientes fue el segundo o tercer embarazo), comparadas con 58,5\% de las controles. También se dio un porcentaje mayor de embarazos menores de 22 semanas en las adolescentes que en las jóvenes adultas y el número de abortos $(20 \%)$ casi duplicó al del grupo control $(11,3 \%)$. De las tres pacientes de 10 años de edad dos abortaron, de las dos de 11 años abortó una y de las nueve de 12 años abortaron tres. Por desproporción cefalopélvica, se practicó cesárea en $51,4 \%$ del grupo de adolescentes contra $37 \%$ del grupo control. Sin embargo, la duración del trabajo de parto fue similar (entre 3 y 15 horas) en ambos grupos, con un promedio aproximado de 8 horas en adolescentes y controles. El análisis estadístico mostró diferencias significativas en el mayor número de complicaciones del embarazo de las adolescentes, especialmente en cuanto a anemia, hipertensión inducida por el embarazo e infección urinaria. Otras complicaciones frecuentes, pero no estadísticamente significativas, en las adolescentes fueron el parto prematuro, el desprendimiento prematuro de la placenta, los desgarros, el sufrimiento fetal y la distocia de rotación. También fue mayor en las adolescentes la morbilidad puerperal, que incluyó abscesos de pared y endometritis.

En el grupo de adolescentes hubo 227 partos y 228 recién nacidos y en el grupo control, 252 partos y 253 recién nacidos (en ambos casos por un embarazo gemelar). La puntuación de Apgar fue $<3$ en $3,1 \%$ de los bebés de las adolescentes frente a 1,19\% de los de las controles; de 4 a 6 puntos en $8,8 \%$ de los hijos de las adolescentes y en $5,53 \%$ de los de las controles, y $>7$ en $88,2 \%$ de los hijos de las adolescentes y en $93,28 \%$ de los de las controles. Del grupo de adolescentes, $16,6 \%$ tuvo niños de bajo peso en comparación con $7 \%$ del grupo control. Hubo una diferencia significativa entre la frecuencia de niños de bajo peso y de niños con un peso de 3500 gramos o más, así como diferencias entre los pesos promedio, que fueron $2930 \pm 539,66 \mathrm{~g}$ en los niños de adolescentes y $3046 \pm 531,75 \mathrm{~g}$ en los de las controles. La talla de los recién nacidos fue similar en ambos grupos, pero la morbilidad perinatal mostró diferencias: fueron prematuros $8,7 \%$ y $5,9 \%$ de los hijos de las adolescentes y de las controles, y mostraron retraso del crecimiento intrauterino $7,9 \%$ de los hijos de las adolescentes y $1,2 \%$ de los de las controles, respectivamente. Además, hubo más intervenciones obstétricas (cesáreas y uso de fórceps) en las adolescentes.

Los resultados de este estudio indican que el embarazo en adolescentes de 14 años y menores es de alto riesgo porque suelen acompañarlo la primiparidad, una situación socioeconómica desfavorable que conduce a la desnutrición y la anemia, un desarrollo insuficiente, falta de control prenatal y viviendas inadecuadas, donde a menudo hay hacinamiento, promiscuidad y a veces incesto. Muchas repiten el patrón de sus madres solteras que también dieron a luz siendo adolescentes. Muy pocas han recibido educación sexual adecuada y algunas empiezan muy temprano a consumir tabaco, alcohol y drogas, que ponen en peligro su salud y la del feto. Pocas acuden a control prenatal $(60 \%$ del grupo de adolescentes no lo tuvo) y su inmadurez física causa problemas de salud que no se resuelven durante el embarazo. 
Para reducir el problema, la autora recomienda dar atención médica integral; educar a padres, maestros y adolescentes; capacitar a los educadores para que organicen programas de educación sexual, y crear centros con programas especiales para adolescentes. La atención obstétrica de estas jóvenes madres requiere trabajo médico en equipos que incluyan psicólogos y trabajadores sociales para fomentar en la adolescente una conducta sexual responsable y dar atención oportuna a los aspectos físicos, emocionales y sociales que forman la personalidad. (Uzcátegui O. Embarazo en la adolescente precoz. Rev Obstet Ginecol Venez 1997;57:29-35.)

\section{Nuevo régimen de profilaxis antituberculosa para pacientes con infección por VIH}

La OMS estima que en el mundo más de cinco millones de personas tienen simultáneamente infección por virus de la inmunodeficiencia humana (VIH) y tuberculosis (TB), enfermedad responsable de alrededor de una tercera parte de las muertes relacionadas con la infección por VIH. Ambas son infecciones sinergísticas que aceleran su mutua progresión. El VIH aumenta la tasa de activación de TB latente, mientras que la TB estimula la replicación del VIH.

Un estudio internacional de 5 años indica que el régimen de tratamiento preventivo antituberculoso de 2 meses es tan eficaz como el de 1 año que se emplea en la actualidad en pacientes con VIH. Según este ensayo aleatorio, patrocinado por el Instituto Nacional de Alergias y Enfermedades Infecciosas (EUA), los Centros para el Control y la Prevención de Enfermedades (EUA) y la OPS, el régimen corto podría reducir considerablemente la morbilidad y mortalidad de pacientes con VIH. Con la participación de cerca de 1600 pacientes con VIH de Brasil, Estados Unidos, Haití y México se compararon los efectos de la administración diaria de rifampicina y pirazinamida durante 2 meses y los de la administración diaria de isoniazida durante un año. Todos los pacientes habían tenido resultados positivos a la prueba de tuberculina, lo que indicaba la presencia de bacilos tuberculosos inactivos. El análisis de los datos obtenidos del estudio mostró que, a los 36 meses de seguimiento, el número de casos de TB fue igual en los dos grupos de tratamiento. Hubo menos muertes en el grupo que tomaba dos medicamentos que en el que tomaba uno, pero la diferencia no fue significativa. Una diferencia importante se refirió al grado de observancia de cada régimen. En el grupo tratado con dos medicamentos, $80 \%$ completaron el tratamiento, mientras que menos de la mitad completaron el régimen de un año. Además, en el con- texto clínico normal son aun menos los que lo completan. De manera que el tratamiento corto no solo mejora la observancia, sino que reduce el costo de los programas de prevención de la TB.

Si bien la rifampicina y la pirazinamida son más costosas que la isoniazida, un programa diario de 12 meses es muy caro en función de los costos administrativos y de personal. El programa de 2 meses bien podría ser mucho más económico para los países que no tienen los recursos para sostener programas de 12 meses. Por otra parte, el régimen abreviado sería también útil para prevenir la activación de la TB pasiva en personas en alto riesgo: contactos de casos de tuberculosis activa; personas infectadas con el bacilo en los 2 años anteriores; lactantes y niños pequeños; usuarios de drogas inyectadas; personas con el sistema inmunitario comprometido, y personas de edad avanzada. (Estados Unidos de América, Institutos Nacionales de Salud, Instituto Nacional de Alergias y Enfermedades Infecciosas. Short-course TB prophylaxis effective in HIVinfected individuals. NIH News Release, Wednesday, Feb. 11, 1998.)

\section{El aumento de peso en pacientes con diagnóstico de cáncer de mama}

En los Estados Unidos, donde una de cada ocho mujeres llega a tener cáncer de mama, más de 180000 mujeres recibirán ese diagnóstico en 1998. En vez de la caquexia que acompaña a muchas formas de cáncer, en las mujeres con cáncer de mama se observa comúnmente un aumento de peso. Este fenómeno no solo tiene un efecto sumamente desfavorable en la calidad de vida de las pacientes, sino que, según los datos más recientes, puede también incrementar el riesgo de recurrencia de la enfermedad y disminuir el tiempo de supervivencia. Si bien el aumento de peso en pacientes con cáncer de mama se conoce ampliamente en el medio clínico, se han hecho pocos estudios para investigar los mecanismos subyacentes. Deben investigarse, por ejemplo, los cambios en el metabolismo, la actividad física y la ingesta dietética como factores posiblemente implicados. Con objeto de fomentar una mejor comprensión del problema y de proporcionar a los profesionales de la nutrición información sobre los factores relacionados, se llevó a cabo una revisión de la literatura.

La prevalencia y la magnitud del aumento de peso parecen depender del tipo de tratamiento recibido. Se ha documentado que el aumento ocurre en presencia de tratamientos sistémicos, es decir, de hormonas y quimioterapia, aun cuando haya náusea, vómito y mucositis. Se asocian con este aumento la administración de prednisona, los regímenes con 
más de un agente anticanceroso, la administración oral y tratamientos de mayor duración. Por el contrario, las pacientes que reciben tratamiento circunscrito al área de la lesión - cirugía con o sin radiacionesno suelen aumentar de peso. El aumento de peso por terapia hormonal (por lo común con tamoxifeno, acetato de megestrol, aminoglutetamida o fluoximesterona) es más pronunciado en mujeres premenopáusicas y en algunos casos es tan notable que obliga a interrumpir el tratamiento. Una razón podría ser el efecto de la terapia sistémica en la función ovárica de mujeres más jóvenes, aunque en las posmenopáusicas quizá se acentúen la disminución del metabolismo y la propensión a acumular grasa propias de esa edad. Las pacientes con cáncer de mama suelen sentir una disminución de su autoestima que se ve acentuada por el aumento de peso. Además, este último predispone a estas mujeres a diabetes, enfermedad cardiovascular y trastornos ortopédicos.

También hay interés en investigar si la obesidad predispone al cáncer. Algunos estudios dan una respuesta afirmativa a esa pregunta y otros indican que en mujeres obesas la enfermedad puede ser incluso más grave en el momento del diagnóstico. Aunque no se ha llegado a un consenso, la mayoría de las investigaciones sobre este tema apuntan a una asociación directa entre la obesidad cuando se hace el diagnóstico y el riesgo de recidiva. Tampoco puede afirmarse con toda certeza que el aumento de peso durante el tratamiento es de mal pronóstico, pero varios estudios confiables indican que a mayor aumento, peor pronóstico. Obviamente, es un campo de estudio que necesita atención inmediata, ya que el aumento de peso puede ser simplemente el marcador de otra causa. De todos modos, los dietistas tienen un papel importante que desempeñar en el desarrollo de planes de nutrición para pacientes de cáncer y también en la investigación de los muchos factores que podrían causar el aumento de peso. Los estudios futuros proporcionarán ideas nuevas y valiosas sobre el problema y llevarán a intervenir efectivamente para mejorar la calidad y longitud de vida de la mujer con cáncer de mama. Hasta que se obtengan esos conocimientos, los practicantes de la dietética tendrán que monitorear individualmente a las pacientes de cáncer de mama y usar enfoques empíricos para lograr la importante meta de controlar el peso. (Demark-Wahnefried W, Rimer BK, Winer EP. Weight gain in women diagnosed with breast cancer. J Am Diet Assoc 1997;97:519-529.)

\section{Criterios para tratar la deficiencia de hierro}

La anemia por deficiencia de hierro es un problema de salud pública de alcance mundial.
Como ha señalado la OMS, $43 \%$ de los preescolares y $37 \%$ de los niños de edad escolar padecen ese tipo de anemia, que causa hipoxia tisular sistémica. Los niños que han padecido esta variante de anemia durante los primeros 24 meses de vida tienen bajo rendimiento escolar y retraso del crecimiento y de las funciones encefálicas, especialmente de la percepción visual y del equilibrio corporal. En edades posteriores la anemia ferropénica puede producir efectos perjudiciales pero probablemente menos graves que en los períodos críticos tempranos. Su principal causa es la deficiencia de hierro, pero a esta se añade la presencia común de insectos y parásitos hematófagos en algunas zonas geográficas.

El hierro es esencial para el metabolismo energético celular y la síntesis de hemoglobina en las células eritroides de la médula ósea. Su ausencia produce eritropoyesis deficiente de hierro y, como consecuencia, anemia microcítica hipocrómica. El contenido de hierro en el organismo se determina midiendo la ferritina sérica, la saturación de transferrina y el hierro hemoglobínico, ya que el hierro se encuentra en equilibrio dinámico entre las moléculas de almacenamiento (ferritina y hemosiderina) y las de transporte (transferrina plasmática y mobilferrina intracelular). El hierro se encuentra transitoriamente fijo en las moléculas funcionales como la hemoglobina y las enzimas férricas y solo se recicla cuando la célula completa su ciclo vital y es fagocitada por los macrófagos.

El organismo obtiene el hierro principalmente de los alimentos sólidos que contienen este elemento. En el individuo normal existen reservas suficientes para equilibrar las variaciones fisiológicas en la exigencia del hierro, por ejemplo, la movilización de ese elemento que se produce en la pubertad, especialmente en las mujeres. Por lo tanto, los adolescentes constituyen una de las poblaciones en riesgo de padecer deficiencia de hierro. Otros grupos en riesgo son los lactantes, las embarazadas y los sangradores crónicos. La lactancia y la edad preescolar son los únicos períodos en los que es posible observar deficiencia de hierro dietética. Están en alto riesgo de esta deficiencia los lactantes alimentados exclusivamente con líquidos pasado el sexto mes de vida y los de bajo peso al nacer, además de los que sufren una hemorragia perinatal. Cuando la embarazada tiene deficiencia de hierro, su influencia en el neonato está parcialmente compensada porque la placenta es capaz de tomar hierro del plasma aunque la concentración sea baja. De modo que las madres con deficiencia de hierro pueden tener hijos con reserva de hierro normal, pero hay indicios de que una deficiencia grave en la madre afectará a los niveles de hemoglobina del niño durante la lactancia. 
Hoy día se cuenta con nuevos conocimientos que facilitan la prevención y el tratamiento de la deficiencia de hierro y México es uno de los países de América Latina en donde se están revisando las estrategias para prevenir y tratar esa dolencia. Anteriormente, una de las dificultades principales era distinguir entre la deficiencia de hierro y las anemias causadas por procesos inflamatorios crónicos, hemoglobinopatías y desnutrición proteínico-calórica. Actualmente, la determinación del receptor soluble de transferrina sérica proporciona una medida de la deficiencia del hierro funcional, que no se modifica cuando se trata de otros padecimientos. Para la profilaxis en grandes grupos de población se ha recomendado enriquecer el azúcar de los lactantes con hierro asociado a ácido acético sódico, ya que el enriquecimiento de alimentos como el pan les cambia el sabor. La suplementación con hierro en tabletas proporcionadas por programas de atención primaria ha sido de eficacia muy limitada debido a los efectos gastrointestinales de las sales ferrosas y a la dificultad de conseguir que los pacientes asistan regularmente al programa. Se considera controvertido establecer programas para toda la población de adolescentes, pues es probable que la mayoría pueda compensar gradualmente la deficiencia con una dieta adecuada en el período pospuberal. Mientras tanto, se intentará ampliar las encuestas sobre el estado nutricional del hierro en la pubertad. Existe acuerdo en que los programas para suplementar de hierro a grandes sectores de la población deben dirigirse a los lactantes y a las embarazadas. Los preescolares se encuentran en posición marginal y en algunas zonas se han incluido en los programas de los lactantes. La suplementación se ha realizado con una sola dosis administrada semanal o bisemanalmente y los resultados indican que la eficacia es comparable a la de una dosis diaria, con la ventaja de ser mejor aceptada y disminuir los efectos gastrointestinales. En clínica pediátrica, el tratamiento individual de casos implica emplear sales ferrosas por vía oral por períodos de 60 a 120 días. Por los riesgos adicionales que entraña, la administración de hierro por vía parenteral debería quedar limitada a casos excepcionales en los que las lesiones del tubo digestivo impiden el uso de la vía oral. (Bello-González SA, Núñez-Villegas NN, Reyes-Pérez R. Actualización de los criterios del tratamiento de la deficiencia de hierro. Bol Med Hosp Infant Mex 1997;54:162-166.)

\section{Situación de la gripe, octubre de 1996 a septiembre de 1997}

Durante la temporada de 1996 a 1997 la gripe fue moderadamente fuerte y causó epidemias en el hemisferio norte, mientras que estuvo menos activa en el sur. Se notificaron con mayor frecuencia los virus $\mathrm{B}$ y $\mathrm{A}(\mathrm{H} 3 \mathrm{~N} 2)$ y con mucho menos frecuencia el A(H1N1). En ambos hemisferios se observó que al comienzo de la temporada, en enero o febrero, las cepas A (por lo general la H3N2) se presentaron después de las B. En mayo de 1997 se aisló en Hong Kong una cepa aviaria, subtipo del H5N1, en un niño que murió del síndrome de Reye. El aislado fue idéntico a los obtenidos de pollos infectados. A pesar de que se detectaron 17 casos más en noviembre y diciembre, no se encontró prueba alguna de que hubiera transmisión interhumana.

Catorce países de la Región de las Américas participaron en la vigilancia mundial de la gripe durante la temporada de 1996 a 1997: Argentina, Brasil, Canadá, Chile, Colombia, Cuba, Guadalupe, Guyana Francesa, Jamaica, Martinica, México, Estados Unidos, Uruguay y Venezuela. La gripe $\mathrm{A}(\mathrm{H} 3 \mathrm{~N} 2)$ y la $\mathrm{B}$ se detectaron en la mayoría de los países. La actividad gripal de A(H3N2) en el Brasil, Canadá, Chile, Colombia, Cuba, Guyana Francesa y los Estados Unidos fue moderada. Ese subtipo causó en Colombia una epidemia que comenzó en agosto y continuó hasta octubre de 1996. La gripe A(H3N2) se esparció por los Estados Unidos y el Canadá durante diciembre y enero. En 122 ciudades estadounidenses se registraron altas cifras de mortalidad por gripe y neumonía, desde la segunda semana de diciembre hasta la segunda de febrero. En la Argentina, Chile y Uruguay ocurrieron brotes de infuenza A que se empezaron a diseminar en agosto. Luego siguió un período en el que se observó la actividad casi exclusiva del virus B. Los últimos aislados obtenidos se caracterizaron en Chile como pertenecientes a los subtipos A(H3N2) y en Uruguay, a $\mathrm{A}(\mathrm{H} 1 \mathrm{~N} 1)$. También se aislaron virus $\mathrm{A}(\mathrm{H} 3 \mathrm{~N} 2)$ en Guadalupe, Martinica y Venezuela. En el Canadá y los Estados Unidos, la actividad de la gripe B empezó a incrementarse en enero y se diagnosticó con mayor frecuencia que la A(H3N2) en febrero y marzo. Se notificaron brotes de la gripe B en el Brasil, Chile, Cuba y Uruguay. También se aisló el virus B en Guyana Francesa y Jamaica durante la temporada referida. (World Health Organization. Influenza in the world: 1 October 1996-30 September 1997. Wkly Epidemiol $\operatorname{Rec} 1998 ; 73: 41-48$.

\section{Consumo de ácido fólico en mujeres estadounidenses de edad fecunda, 1997}

Todos los años en los Estados Unidos cerca de 4000 embarazadas tienen niños con espina bífida o anencefalia. Los que nacen con espina bífida suelen 
sobrevivir con graves discapacidades, pero la anencefalia es siempre mortal. Sin embargo, se sabe que el ácido fólico, que forma parte del complejo vitamínico B, reduce la incidencia en $50 \%$ o más si se toma diariamente antes de concebir y en la etapa temprana del embarazo. Por lo tanto, en 1992 el Servicio de Salud Pública de ese país recomendó que todas las mujeres de edad fecunda expuestas a embarazo consumieran $400 \mathrm{mg}$ de ácido fólico todos los días.

En enero y febrero de 1997 se realizó una encuesta telefónica de una muestra estratificada de 2001 mujeres de 18 a 45 años de edad para evaluar sus conocimientos sobre el ácido fólico y el uso de vitaminas. Solo una tercera parte de las encuestadas tomaban suplementos con la cantidad de ácido fólico recomendada. En general, $64,4 \%$ de ellas tomaban algún tipo de suplemento vitamínico; $44,3 \%$ tomaban suplementos con ácido fólico pero no todas lo hacían diariamente, y 20,1\% usaban otros suplementos que no contenían ácido fólico. El uso de esta vitamina fue mayor entre las mujeres de 25 años de edad en adelante, las que tenían instrucción universitaria y las de ingresos más altos, así como en las casadas y las de raza blanca. De las que conocían la recomendación sobre el ácido fólico, 45,2\% lo tomaban diariamente, comparadas con $28,8 \%$ de las que lo tomaban sin ese conocimiento. La mayoría de las mujeres que no tomaban los suplementos diariamente dieron como razones que se les olvidaba hacerlo, que pensaban que no los necesitaban, que no tenían suficiente información al respecto y que las vitaminas eran muy caras.

Dada la importancia de evitar defectos congénitos como los del tubo neural, es necesario impartir más información a todas las mujeres de edad fecunda sobre la función preventiva que desempeñan el ácido fólico y otras vitaminas. Puesto que muchas mujeres toman otros suplementos, con campañas de publicidad enfocadas en las de edad fecunda sería fácil conseguir que añadieran el ácido fólico a su dieta diaria. Además, el estudio mostró el menor consumo de la vitamina en las mujeres de grupos minoritarios y de menos ingresos, lo cual sugiere que la disponibilidad del ácido fólico a precio reducido estimularía su uso en esos grupos. La Administración de Alimentos y Medicamentos de los Estados Unidos ha establecido que, a partir de enero de 1998, se enriquezcan con ácido fólico los cereales en grano. Para consumir la cantidad recomendada, cada mujer tendrá que comer cereal enriquecido que contenga el valor diario total de ácido fólico o aumentar su consumo de alimentos enriquecidos, como pan, arroz o pasta, así como de otros alimentos ricos en folatos, como el jugo de naranja y las legumbres verdes. (U.S. Centers for Disease Control and Prevention. Use of folic acidcontaining supplements among women of childbearing age-United States, 1997. MMWR [publicación periódica en línea] 1998;47(7): [4 pantallas]. Se consigue en: URL: http://www.ama-assn.org/ special/womh/newsline/special/mmwr4707.htm) 